\title{
Chapter 2 \\ Planning, establishment and management of pastures in high country
}

\author{
B.E. Allan, W.L. Lowther and P. J. Walton \\ Tara Hills Research Station, MAF, Omarama \\ Invermay Agricultural Research Centre, MAF, Mosgiel \\ Mt Stalker, Maheno, North Otago
}

\section{INTRODUCTION}

Introduced pasture species are used to improve the quantity and quality of feed grown in the South Island high country. However, matching the increased feed supply to annual stock demands is difficult in an environment characterised by long winters, unpredictable climate and rugged terrain.

Every high country run faces a different set of problems, and because of this, no set recipe can be given. Nevertheless, when undertaking a development programme, there are many points that need consideration. This paper recommends how to approach development and, within our present know how, how to get the most from it.

\section{RESEARCH YOUR RESOURCE}

First, build a plan of your property which includes all the resources. The thorough researching of your property cannot be over emphasised. Before you start development you should employ the services of experienced people to map in detail your run for soil type, aspect and steepness of terrain. This is important, for flats, sunny and shady faces all have different fertilizer requirements, and vastly different management requirements. In order that you do not start an uneconomic development, it is necessary today to know not only your soil acidity and levels of olsen $\mathrm{P}$, sulphur, potassium and calcium but also trace element status and the phosphate retention. Part of your resource plan should include location of natural water, potential for irrigation dams and future stock water, and location of tracks for both stock and vehicles,

Until you have established what resources you have, you do not have the knowledge to start development, or run a farming business.

\section{DEFINE YOUR LIMITATIONS}

Money supply and personal attitude to both development and its results are very necessary requirements that differ greatly from person to person. For the purposes of this paper these aspects are not considered as limitations. However, all budgeting should be done at current and projected market interest rates, regardless of attractive offers from government or other sources. Finance sought on a long-term mortgage basis must be from a secure source that is not subject to major changes in repayment.

When defining limitations it is necessary to look at your property to determine what is holding back its development. It could be a summer or winter feed deficit, acid soils, lack of rainfall, poor access, or simply poor management. At this point you must use your resource inventory to decide if the run has the land capable of filling the gap. For instance, if the property is suffering a winter feed deficit, then development in some areas such as shady aspects will only aggravate the situation. Alternatively, if a summer shortage is the problem, irrigation or oversowing some higher and wetter country must be considered.

Development is often undertaken where it is cheapest and easiest rather than where needed. The past easy access to cheap government finance has helped to fuel this problem. Once again we emphasise, define you property's limitations.

\section{OVERSOW TO IMPROVE ANNUAL FEED SUPPLY}

\section{Site preparation}

Dense vigorous vegetation can reduce both germination and survival of seedlings. If such country is to be oversown, natural roughage should be cleared either by using large mobs of sheep or cattle or if necessary, burning. However, complete removal of cover can result in poor establishment, particularly on dry sunny faces. Here burning should be contemplated in the season prior to oversowing. 


\section{The time to oversow}

The best time to oversow varies from earlyAugust on low-sunny faces to late-September on higher shady-faces. Later oversowing is not advised, for early onset of dry conditions can seriously reduce establishment.

Opinions differ over whether grass seed should be included in the initial oversowing mixture. Because of the low nitrogen status of tussock grassland soils, grasses make little contribution to dry matter production in the early years. The important point here is not when to oversow grasses, but that at some stage they should be oversown, particularly on wintering blocks. If grass seed is applied later in the development programme, careful grazing is necessary to reduce competition during establishment.

\section{Inoculation and pelleting}

Inoculation of seed is a necessity, for the rhizobia needed to nodulate clover, lucerne and lotus are absent from most areas of tussock grassland. It is only where haresfoot trefoil is abundant that satisfactory populations of clover rhizobia are guaranteed, and inoculation is not essential for clover, but it is still needed for lotus or lucerne.

However if in doubt, inoculate, for compared to overall costs it is a cheap insurance.

Pelleting of inoculated clover and lucerne seed is recommended because it enhances survival of rhizobia on the seed both before and after oversowing. Pelleting is most effective when oversowing in conditions marginal for rhizobia survival and seedling nodulation, such as those on dry sunny faces, bare soil surfaces and acid soils. In contrast to clover and lucerne, Maku Lotus pedunculatus has shown little response to seed pelleting. The present recommendation is to slurryinoculate the seed using up to five-times the manufacturers recommended rate of peat inoculant. The incorporation of $10 \%$ gum arabic in the slurry improves the viability of rhizobia on the seed and the inoculated seed can be stored for up to two weeks before sowing.

On molybdenum deficient soils the addition of molybdenum to the seed coat ensures an immediate supply to all seedlings. Similarly, sulphur containing pellets are recommended for use on sulphur deficient soils although sulphur fertilisers are still required.

Coating of grass seed may increase establishment of oversown grass in a few cases through improved germination. However advantage remains doubtful as results are highly inconsistent and depend on both site and season.

\section{Grazing management during establishment}

The use of large mobs of stock to trample seed into the soil immediately following oversowing can greatly improve seedling establishment. This is especially true for denuded semi-arid areas where dry conditions for short periods can prevent germination. However, for this practice to be successful, subdivision fencing must be planned and erected before oversowing.

Seedling growth is generally slow, depending on location, climate and species oversown. Grazing should be deferred until seedlings are well established which in most environments may not be until the autumn following sowing. Dense grass swards, such as browntop, are an exception. Here strategic grazing during the establishment year is advised to reduce competition from the existing grass sward.

Grazing of Maku lotus must be avoided during the establishment year for seedling growth is very slow. Following this first year, careful grazing of Maku is necessary to encourage plant spread. Recent research has shown Maku spread results mainly from autumn growth of underground rhizomes, and grazing over the January to March period restricts this spread.

\section{TOPDRESS PRUDENTLY}

Fertiliser requirements are discussed elsewhere (see Chapter 1). However, maintenance fertiliser usage should be based on your resource research. Request special mixes depending on specific block requirements for phosphorus, sulphur, lime, nitrogen and molybdenum. Apply only the minimum necessary for that block, depending on the utilisation intended. With planning and understanding, considerable financial savings can be made.

\section{FENCE EFFECTIVELY}

All too often fencing is not given enough priority in a development programme. Fences do not grow or eat grass, however they are essential for the efficient conversion by stock of feed into saleable products. The type of fencing is not important, so long as it is effective. However for cheapest subdivision of difficult terrain, electric fences and solar panels should be considered. Appreciation of aspect is very important when planning subdivision, particularly where improved sunny blocks are the main winter feed source.

\section{UTILISE TO SURVIVE}

Grazing management objectives are to convert feed grown into saleable products in the most efficient'way possible. However, the system must be sustainable. 


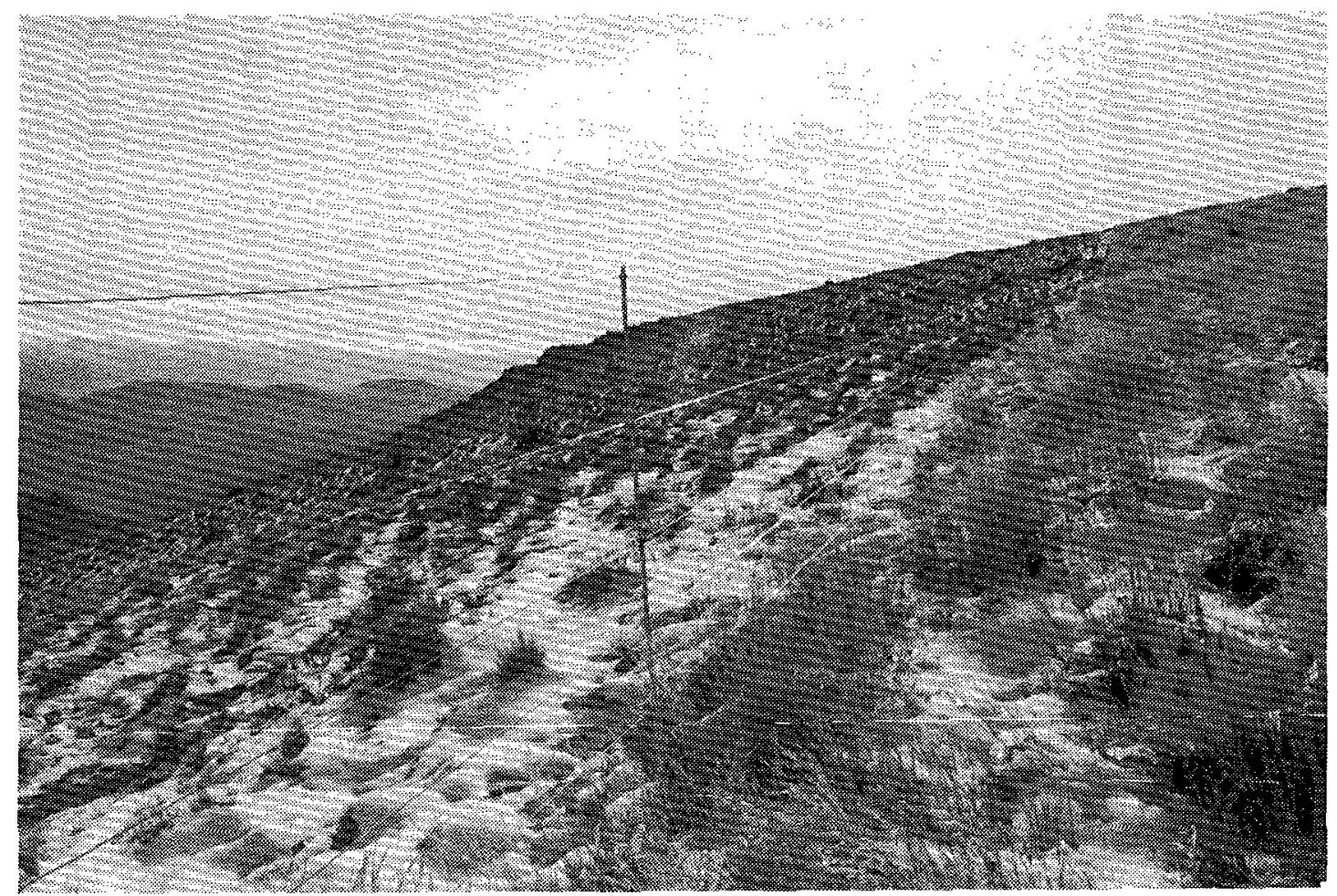

Effective grazing _control of oversown high country can be achieved with electric fencing. Here the 5 wire and fibreglass fence is powered by a solar panel.

The winter feed deficit is likely to remain the major problem and in some areas early spring and mid-summer may also be pinch periods. Sunny faces up to mid-altitude levels $(900 \mathrm{~m})$ can be utilised throughout winter, for snow risk here is less than on the flats. During winter, stock should be mobbed up as much as possible. If all-grass wintering is contemplated some hay or silage should be on hand as an insurance to carry the increased stock numbers through unusually severe winters. These sunny faces also make excellent lambing blocks, provided there is some relief from grazing in early spring. Silage should be considered as a high quality feed alternative during this period. Subdivision is needed on sunny faces for budgeting winter feed, even spread of ewes during lambing and mobbing up for rotational grazing following marking.

Shady faces should be utilised during the growing season. The warmer of these are best for lambing and mating, while those colder or higher provide good summer pasture for young stock. Here clovers are of major importance. Only white and alsike clovers should be oversown, for under the higher levels of utilisation intended, contribution from red clover will be insignificant. Alsike will contribute most initially, but as its growth form is closer to that of red, it will not persist as well as white clover. Apanui cocksfoot will respond to moderate grazing levels provided frequent spelling is allowed. In contrast, Nui ryegrass is more suited to higher grazing pressures, but may not be as productive in dry summers, and will not withstand severe winter conditions on cold shady faces above $750 \mathrm{~m}$ altitude.

\section{Subdivision is essential}

Rotational grazing improves the evenness of utilisation within blocks, and creates a feed bank ahead of stock, thereby helping annual feed supply to meet annual feed demand. As a guideline, blocks should be small enough to allow mobs to achieve $60-70 \%$ inter-tussock utilisation within a 7-10 day grazing period. There should be sufficient blocks within any rotation to allow at least 3-4 weeks regrowth. In most cases at least $\mathbf{3 0}$ hill blocks are needed to operate an effective management system. More blocks mean greater flexibility and control, and therefore greater peace of mind. Following lambing a grazing density of $50 \mathrm{SU} / \mathrm{ha}$ is a desirable goal, but in many areas, remoteness, topography and lack of stock water will make achievement of this difficult.

Development of the lower altitude sunny faces and elevated fans can provide valuable early spring feed, giving some relief to the lambing blocks. Lucerne should be oversown or direct drilled here on 
runs with less than $500 \mathrm{~mm}$ (20") rainfall, for white clover will not persist.

Irrigated grass/clover, red clover or lucerne on the flats can alleviate the summer dry problem, but where this is not possible Maku lotus should be oversown at higher altitudes (up to $1500 \mathrm{~m}$ ). Here soils are less fertile, but temperature rather than moisture is limiting. An advantage from this is that in very dry summers, temperatures are generally warmer, ensuring even greater lotus production.

The key to successful management of improved tussock country, as for cultivated lowland, is controlled utilisation. Control prevents both loss of introduced species through over-grazing and loss of pasture quality through undergrazing. Utilisation means effective conversion of feed into animal products, thereby providing dollars for fertiliser and debt servicing. Stock numbers must be increased in accordance with increased pasture production, and fencing must be carefully planned to facilitate easy but flexible management.

\section{SUMMARY}

1. Research your resource. Until you know your resource, you do not have the knowledge to shar development. Soil mapping and testing are essential.

2. Define your limitations. Development is often done where it is cheapest and easiest, rather than Where needed. Feed deficits or pinch periods' must be defined:

3. Oversow to teduce feed deficits. Reduce compenition if necessary. Oversow in early spring; inoculate legumes and include grass species.

4. Topdress with prudence. Request specific mixtures depending on nutrient requirements and intended use of specific blocks.

5. Fence effectively. Fences are an integral part of development. The type is not imbortant, but it nust be effective.

6. Utilise to survive. The improved feed supply nust be efficiently utilised. Rotational grazling improves the evenness of utilisation and creates a feed bank ahead of stock, hereby helping annual feed demand. For each block a balance between efficient utilisation and sustained productivity from the desired species must be achieved

\section{FURTHER READING}

1984 High Country Field Day (Tara Hills). Regional Information Centre, Ministry of Agriculture and Fisheries, Invermay. Allan B.E. 1985. Grazing effects on pasture and animal production from oversown tussock grassland. Proceedings of the New Zealand Grassland Association 46, 119-125.

Proceedings of the 1982 Merino and Halfbred Producers Seminar, Lincoln College. Fine Wool.

Lowther W.L. 1977. Factors affecting the response of clover establishment to inoculation and pelleting. Proceedings of the New Zealand Grassland Association 38(1), 175-181.

Proceedings of the 1979, 1981 and 1983 Hill and High Country Seminars, Lincoln College.

White J.G.H. 1973. Improvement of hill country pastures. p. 259-290. In: Langer R.H.M. editor. Pasture and pasture plants. A.H. \& A.W. Reed, Wellington. 


\section{Discussion}

\section{PART I - SOUTH ISLAND HILL AND HIGH COUNTRY}

Q. Has Russell lupin potential in this environment?

A. It appears to be most promising in situations where soil fertility is moderate.

Q. Could you explain why you indicate red clover being more suitable than white clover under cooler temperatures in high country?

A. In this situation red clover lasts longer as autumn-saved herbage than white clover which becomes slushy with onset of the first frost,

Q. A re there any risks in farming low er fertility drier areas?

A. Yes, especially economic viability during the next 5 years. Much of the high country is farmed at the lower fertility level, but problems such as ingress of Hieracium are not seen as hopeless, and shouid not be severe constraints on farming in high country.

Q. Does the available range of species and cultivars actually limit development of high country pastures, or would further selection and breeding of grasses and legumes be worth while?

A. Available cultivars are not the most suitable. To be certain of a future for farming this region we need species and cultivars which require less fertiliser, are more persistent and can extend seasonal growth.

The major constraints on farming of high country are temperature, moisture and especially soil fertility, but we can produce significant changes using better species and cultivars.

Q. In Scottish high country, heather plays a major role as a herbage plant. W ould this or similar plants have potential in South Island high country?

A. Some tussock grasses, especially blue tussock, play a similar role as browsing plants in winter and are most valuable during snow storms, when lower growing species are covered.
Q. Do different species of grazing animal offer options for high country farmers?

A. Type of livestock used must be considered during planning development of pastures. The resources available determine the type of animal used. For example, where the shrub sweet briar (Rosa eglantaria) is widespread, goats can be farmed. By applying appropriate stock, to available herbage we can use sheep in the dry natural grasslands, goats in shrublands, deer in the forest-shrubland transition. Unfortunately, all current recommendations are still based on grazing work with sheep, and current research is revealing different trends under other types of stock.

Q. To what extent are the carbohydrate reserves of plants important in surmounting the no-growth period during winter? What management strategy is used to overcome this problem?

A. The traditional strategy has been conservation of herbage to feed out during winter, though some sunny aspects do support pasture growth during winter. All-grass wintering is now popular but less efficient than conservation in that much summer growth is sacrificed by carrying herbage over into autumn-saved pasture or standing hay. Use of silage will probably become more important in future. It enables production of a better quality feed and allows better management of upgraded pastures.

Q. Does long spelling of pastures during winier increase persistence of some herbage species?

A. Yes. It is also better to spell pasture before onset of cool weather, to obtain some regrowth then.

Q. Has any progress been made on use of exotic grazing animals such as Ilamas, alpacas and vicunas from South America?

A. Problems have been encountered in supply of these from some countries which apply export restrictions. Alpacas and vicunas seem to have some potential. 